\title{
DESENHOS E DEPOIMENTOS: RECURSOS PARA INVESTIGAÇÃO DA PERCEPÇÃO E DO CONHECIMENTO VOCAL
}

\section{Drawings and statements: resources for the investigation of perception and vocal recognition}

\author{
Priscila Fabiana Agostinho Pereira ${ }^{(1)}$, Regina Zanella Penteado ${ }^{(2)}$
}

\begin{abstract}
RESUMO
Objetivo: caracterizar, em desenhos e depoimentos sobre a voz, os aspectos de percepção e de conhecimento vocal em participantes de grupos de vivências de voz. Métodos: análise documental de relatórios finais de quatro grupos de Vivência de Voz realizados nas disciplinas Estágio em Fonoaudiologia Comunitária I e II de um Curso de Fonoaudiologia para análise de conteúdo dos desenhos e depoimentos escritos de 53 sujeitos. Resultados: as categorias identificadas pela análise dos desenhos e dos depoimentos foram: imagem vocal ou valoração atribuída à voz - com freqüência da imagem/valoração positiva nos desenhos e negativa nos depoimentos. Quanto aos atributos vocais, houve freqüência do atributo auditivo-proprioceptivo, com menor ocorrência dos atributos sócio-cultural, psico-emocional e profissional. Os parâmetros vocais com maior ocorrência foram os de loudness, pitch, articulação e qualidade vocal. Conclusão: desenhos e depoimentos escritos sobre a voz se mostram como recursos que podem possibilitar a expressão da percepção e conhecimento dos sujeitos acerca da sua voz e necessitam ser melhor explorados nas ações educativas fonoaudiológicas que prezam pela troca de saberes, diálogo e participação ativa dos sujeitos, coerentes com a perspectiva da promoção da saúde.
\end{abstract}

DESCRITORES: Voz; Promoção da Saúde; Educação em Saúde

\section{INTRODUÇÃO}

Na literatura fonoaudiológica nota-se a primazia do olhar científico nos processos de avaliação vocal e poucos estudos estão voltados para a investigação do prisma dos sujeitos envolvidos nas ações: o que ele pensa, sabe, conhece e como percebe a sua voz. Poucos são os estudos que

(1) Fonoaudióloga pela Universidade Metodista de Piracicaba.

(2) Fonoaudióloga; Docente do Curso de Fonoaudiologia da Universidade Metodista de Piracicaba; Especialista em Linguagem; Especialista em Voz; Especializanda em Ergonomia pela Universidade Metodista de Piracicaba; Mestre e Doutora em Saúde Pública pela Faculdade de Saúde Pública da Universidade de São Paulo. empregam estratégias alternativas às tradicionais entrevistas ou questionários para abordar o conhecimento e a percepção dos sujeitos sobre a própria voz ${ }^{1-3}$

Assumir o paradigma da Promoção da Saúde nas ações fonoaudiológicas implica em buscar constituir processos avaliativos e educativos que, pautados pelo diálogo, favoreçam a participação ativa dos sujeitos e propiciem a capacidade de expressão e a troca de conhecimento acerca dos aspectos contextuais, sociais, subjetivos e culturais que influenciam as percepções dos sujeitos sobre seu processo saúde-doença-cuidado ${ }^{3-5}$. A ação educativa se faz fundamental para a promoção da saúde, na perspectiva de se criar condições para que as pessoas se capacitem para reconhecer suas necessidades e expressá-las, com autonomia para tomar decisões a respeito de aspectos que afetam os seus processos saúde-doença $^{6,7}$. Diversos autores afirmam a importância 
de se levar em conta os processos subjetivos, identitários e culturais nas ações educativas ${ }^{8-14}$.

$\mathrm{Na}$ área de voz, faz-se, portanto, necessário o investimento em ações educativas grupais, coletivas ou comunitárias que possam oferecer subsídios para a orientação e fundamentação de mudanças necessárias no sentido de promover a capacitação dos sujeitos como agentes de sua saúde por meio de estratégias metodológicas que levam em conta a subjetividade e o ponto de vista dos sujeitos sobre a sua própria saúde (vocal) e que possibilitam a expressão do seu conhecimento, do seu saber e das suas maneiras de perceber a própria voz ${ }^{3}$.

O processo de avaliação da voz - parte integrante importante de uma ação em saúde vocal - representa a oportunidade do sujeito se deparar com as suas condições de saúde, significando e (re) interpretando seu processo saúde-doença. Desta maneira, o conhecimento, a percepção e participação dos sujeitos envolvidos não podem ser subestimados ou desconsiderados; pelo contrário, são aspectos que precisam ser valorizados, viabilizados e melhor explorados sendo que, para tanto, é preciso buscar construir caminhos no contexto de uma prática que valorize a integração de saberes - acadêmico e popular - na construção conjunta do conhecimento em saúde vocal ${ }^{3}$.

O desenho está no foco de poucos trabalhos fonoaudiológicos, sendo que a maioria deles se trata de pesquisas desenvolvidas por estudiosos da área de linguagem e são poucos aqueles que empregam o uso do desenho na área de voz.

No contexto clínico, alguns autores ${ }^{15}$ empregaram desenhos da própria pessoa e da sua voz como componentes da avaliação de sujeitos disfônicos. Os autores afirmam a importância dos desenhos, como meio simbólico de comunicação e de expressão de conteúdos psíquicos inconscientes e de características psicológicas, de personalidade, cognitivas, afetivas, comportamentais e corporais. Aanálise de desenhos e das cores, para estes autores, pode trazer conteúdos e contribuições para ações futuras e soluções de problemas no contexto terapêutico.

Estudos ${ }^{16}$ voltados para o uso do desenho na clínica fonoaudiológica com crianças concluíram que este vem sendo empregado em processos avaliativos e terapêuticos em linguagem oral, escrita, motricidade oral e voz (estes últimos como auxiliar na realização de exercícios) e também considerado um recurso auxiliar na vinculação terapeuta-paciente. As autoras sugerem a ampliação de pesquisas fonoaudiológicas a respeito do desenho.

Desenhos de crianças disfônicas foram utilizados em estudos ${ }^{17}$ para avaliar a compreensão dos pacientes acerca dos objetivos do processo terapêutico fonoaudiológico na clínica de voz, afirmando o valor dos desenhos como recursos expressivo e avaliativo.

Desenhos e depoimentos foram utilizados para investigar o conhecimento sobre a voz de estudantes de Comunicação Social - Habilitação Jornalismo ${ }^{18,19}$, empregando metodologia similar à da pesquisa que ora se apresenta, e os resultados indicam que desenhos e depoimentos sobre a voz se mostram como recursos que possibilitam a expressão dos sujeitos acerca da voz e saúde vocal, aspectos que necessitam ser melhores explorados nas ações fonoaudiológicas.

Na presente pesquisa, o interesse pelo desenho não está na exatidão de suas formas, mas sim enquanto sistema de representação simbólica e possibilidades de projeção do esquema corporal e da própria imagem (vocal) refletida no papel, de comunicação, de significação, de objetivação de sentimentos, pensamentos, conhecimentos e de expressão da subjetividade, da cultura e de modos de participação ${ }^{17,20-24}$. Aqui, entende-se que desenhar sobre a própria voz é uma oportunidade de o sujeito pensar sobre ela, as suas características e os aspectos intervenientes na qualidade e saúde vocal, bem como de expressar o conhecimento, a experiência e as percepções relacionados à voz e de refletir sobre estes.

O objetivo deste estudo é caracterizar, em desenhos e depoimentos sobre a voz, os aspectos de percepção e de conhecimento vocal, na perspectiva de contribuir para que os aspectos de subjetividade, da cultura, do saber e da perspectiva dos sujeitos envolvidos possam ser melhores investigados e explorados nos processos avaliativos e nas ações educativas e terapêuticas da área de voz.

\section{MÉTODOS}

Os sujeitos dessa pesquisa são participantes dos Grupos de Vivência de Voz, desenvolvidos como parte das ações da disciplina Estágio em Fonoaudiologia Comunitária I e II do Curso de Fonoaudiologia da Universidade Metodista de Piracicaba (UNIMEP). Tais grupos constituem-se por procura espontânea de sujeitos da cidade de Piracicaba, de ambos os sexos e com idades entre 15 e 80 anos que fazem ou não uso profissional da voz. São integrantes da comunidade acadêmica (funcionários, professores, universitários) ou não, como educadores e professores da rede pública e particular, cantores, atores, advogados, jornalistas, radialistas, locutores, pastores, profissionais de turismo, vendedores, palestrantes, músicos e vocalistas de bandas de diversos estilos musicais (MPB, "country", rock, forró, gospel, pagode, sertanejo e caipira), além de donas de 
casa, praticantes de capoeira, integrantes de grupos corais e de louvor de diversas igrejas.

Os Grupos de Vivência de Voz desenvolvem-se em encontros semanais de uma hora e meia, durante um semestre, quando são abordados diversos temas e conteúdos, dentre eles o da avaliação vocal dos participantes ${ }^{3,7}$. Os grupos são desenvolvidos com número variável de participantes, entre 10 e 30 , em média 20.

Nestes grupos, logo nos primeiros encontros, uma das atividades realizadas implica no oferecimento, aos sujeitos, de papel sulfite e canetas coloridas sob a seguinte instrução: "faça um desenho sobre a sua voz, uma imagem que a represente e, a seguir, escreva um depoimento sobre a sua voz".

Tais produções gráficas (o desenho e o depoimento) são apresentadas para os participantes do grupo e depois anexadas ao corpo do relatório final, elaborado pelos alunos estagiários do Curso, sob supervisão docente. Nota-se, entretanto, que os desenhos e depoimentos sobre a voz não vêm se configurando como objetos de análise e de interpretação no processo avaliativo vocal.

O presente artigo se refere à pesquisa qualitativa que analisa relatórios finais de quatro grupos de Vivência de Voz para o levantamento de dados - os registros dos desenhos e depoimentos escritos sobre a voz. Foram incluídos os sujeitos que continham os registros de desenhos e de depoimento e excluídos aqueles que não continham um dos dados (ou que faltaram no dia em que a atividade foi realizada), de maneira que a pesquisa foi realizada com 53 sujeitos.

Buscou-se analisar os desenhos e os depoimentos nas suas possibilidades de expressão e representação do conhecimento, do saber e da percepção que os sujeitos têm da sua voz, levando-se em conta a sua representatividade. A análise se dá no sentido de se identificar conteúdos e/ou temas ${ }^{25}$ aos quais as produções remetem ou se referem. Feita a análise de conteúdo/análise temática, realizada a partir dos procedimentos de pré-análise, exploração do material e tratamento dos resultados. Na pré-análise serão realizadas observações dos desenhos e várias leituras dos textos dos depoimentos, permitindo aflorar os sentidos e descobrindo impressões e orientações para a análise. A exploração do material possibilitou identificar temas e conjuntos temáticos, bem como selecionar imagens e trechos significativos e identificar conteúdos e núcleos de sentidos que orientem recortes e agregações na organização do material em categorias temáticas que se referem às percepções e conhecimentos dos sujeitos. Os desenhos e trechos dos depoimentos são classificados e categorizados em função da imagem sobre a voz/ imagem vocal e também de alguns atributos relacionados à voz, orientado por estudos anteriores ${ }^{18,25}$ e também em função de alguns parâmetros vocais como: articulação, loudness, qualidade vocal, pitch, respiração/coordenação pneumofônica, velocidade de fala e ressonância ${ }^{26}$.

A imagem vocal é classificada como entre predominantemente positiva ou negativa, mista ou neutra. É considerada imagem/valoração mista quando um mesmo material explicita conteúdos positivos e negativos; enquanto que a imagem/valoração neutra é a ausência de expressão de imagem vocal e/ou de valoração da voz.

No que diz respeito aos atributos, são considerados aqueles já identificados em estudos anteriores que se valeram da mesma metodologia da presente pesquisa ${ }^{18}$, quais sejam: a) auditivo-proprioceptivo, o qual se refere aos aspectos relacionados à percepção auditiva da voz e às sensações proprioceptivas na produção vocal; b) sócio-cultural, o qual remete às percepções referentes aos aspectos de interação social, atividades sociais e culturais, de comunidade e de grupos sociais; c) profissional, o qual compreende as percepções referentes aos aspectos relacionados aos traços e opções de acordo com a profissão e as necessidades no serviço profissional; e d) psico-emocional, o qual engloba as percepções referentes a aspectos emocionais e psicológicos.

$\mathrm{O}$ projeto que originou a presente pesquisa foi aprovado pelo Comitê de Ética e Pesquisa da UNIMEP sob n 76/04, em 21/12/2004.

\section{RESULTADOS}

Houve maior freqüência da imagem/valoração positiva nos desenhos e da imagem/valoração negativa nos depoimentos escritos, ambos com 20 (37\%) ocorrências. A imagem/valoração mista foi observada em 10 desenhos (20\%) e em 13 depoimentos $(24 \%)$ e a neutra em 8 desenhos (15\%) e em 6 depoimentos (11\%). Uma vez que a ocorrência da valoração mista refere-se à conjunção de imagem vocal ou valorações positiva e negativa, pode-se considerar que, somando-se a ocorrência isolada com a mista, a ocorrência total de valoração positiva e negativa foi de aproximadamente $30(57 \%)$ para desenhos e $33(62 \%)$ para depoimentos.

Alguns resultados de trechos de depoimento escrito e desenhos são apresentados nas Figuras 1, 3,6, 8 e 9 .

As Figuras 2, 4, 5 e 7 apresentam os resultados da categoria atributos relacionados à voz e as Figuras de 10 a 12 da categoria dos parâmetros vocais. Abaixo, o depoimento escrito do sujeito 34 expressa os atributos auditivo-proprioceptivo e sócio-cultural 
e os parâmetros vocais de articulação e velocidade de fala:

(S.34) - "Usei a bala ardida porque às vezes arde minha garganta, geralmente quando canto, chego até a afogar; usei a corda porque, às vezes, eu me enrolo no falar; usei o cadeado porque, às vezes, eu prendo a bochecha para falar; usei o trem porque, às vezes, falo rápido e as pessoas não me entendem (...) também às vezes eu grito sem perceber; e eu preciso da minha voz perfeita para agradar ainda mais ao meu Deus e não deixar ninguém surdo".

A Figura 1 refere-se aos desenhos do sujeito 34 e expressa os atributos auditivo-proprioceptivo e sócio-cultural e os parâmetros de articulação e velocidade de fala.

A Figura 2 expressa a distribuição dos resultados de desenhos e depoimentos sobre a voz conforme o atributo auditivo-proprioceptivo.

O depoimento escrito do sujeito 9 expressa os atributos sócio-cultural e profissional:

(S.9) - "os círculos unidos representam o convívio social, onde minha voz é um vínculo de ligação" e "minha voz é como instrumento de trabalho".

A Figura 3 apresenta os desenhos do sujeito $9 \mathrm{e}$ expressa os atributos sócio-cultural e profissional.

A Figura 4 expressa a distribuição dos resultados de desenhos e depoimentos sobre a voz conforme o atributo sócio-cultural.

A Figura 5 expressa a distribuição dos resultados de desenhos e depoimentos escritos sobre a voz conforme o atributo profissional.

O depoimento escrito do sujeito 4 expressa o atributo psico-emocional:
(S4) - "eu acho minha voz de criança".

A Figura 6 apresenta os desenhos do sujeito $4 \mathrm{e}$ expressa o atributo psico-emocional.

A Figura 7 mostra a distribuição dos resultados de desenhos e depoimentos escritos sobre a voz conforme o atributo psico-emocional.

O depoimento do sujeito 8 expressa o parâmetro qualidade vocal:

(S.8) - "A minha voz é como o fogo: apaga e acende; precisa de lenha para se manter, só que a minha fogueira nunca se mantém no mesmo nível. Quando necessito que a chama se mantenha ela me deixa na mão."

A Figura 8 apresenta os desenhos do sujeito $8 \mathrm{e}$ expressa o parâmetro qualidade vocal.

O depoimento do sujeito 47 expressa os parâmetros: loudness, pitch, qualidade vocal e respiração/coordenação pneumofônica.

(S.47) - "minha voz começa baixinha e fina; de repente aumenta e se quebra com falta de fôlego".

A Figura 9 apresenta os desenhos do sujeito 47 e expressa os parâmetros: loudness, pitch, qualidade vocal e respiração/coordenação pneumofônica.

A Figura 10 apresenta a distribuição dos resultados da análise de desenhos e depoimentos segundo os parâmetros vocais de articulação e loudness.

A Figura 11 mostra a distribuição dos resultados da análise de desenhos e depoimentos segundo os parâmetros vocais: qualidade vocal e pitch.

A Figura 12 apresenta a distribuição dos resultados da análise de desenhos e depoimentos segundo os parâmetros vocais: respiração/coordenação pneumofônica, velocidade de fala e ressonância.

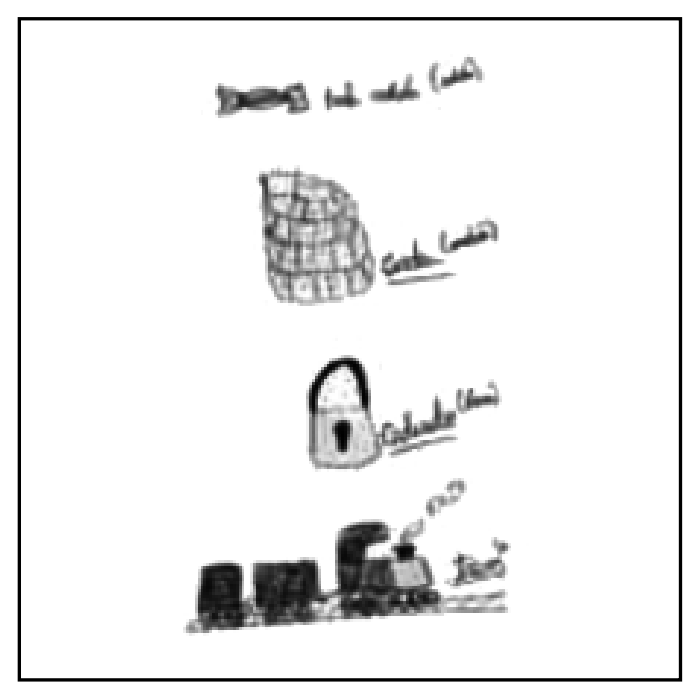

Figura 1 - Desenhos do sujeito 34: atributos auditivo-proprioceptivo e sócio-cultural e parâmetros de articulação e velocidade de fala 


\begin{tabular}{|c|c|c|}
\hline \multicolumn{3}{|c|}{ ATRIBUTO AUDITIVO -PROPRIOCEPTIVO } \\
\hline Suj. & Desenho & Depoimento \\
\hline 1 & pato, árvore, nuvem e sol & minha voz parece de pato \\
\hline 2 & notas musicais & eu considero minha voz estavel \\
\hline 6 & boca, notas musicais, mulher cantando & $\begin{array}{c}\text { minha voz é bonita, mas dificil de alcancer } \\
\text { altura }\end{array}$ \\
\hline 10 & quarto, cama e pés & $\begin{array}{c}\text { minha voz parece com grenihos vindo de um } \\
\text { quarto de motel }\end{array}$ \\
\hline 11 & homem soltando a voz, que entra num poço vazio & $\begin{array}{l}\text { quando eu cants a minha voz parece qua vai } \\
\text { para o profundo do pop̧o }\end{array}$ \\
\hline 12 & rosto, boca tapada & $\begin{array}{l}\text { quando tenho que soltar a voz e como se eu } \\
\text { tivesse gritando }\end{array}$ \\
\hline 13 & montanha, árvore, pessoas e passaros & $\begin{array}{l}\text { minha voz precisa de um ajuste, pois tenho } \\
\text { falha }\end{array}$ \\
\hline 16 & árvore e uma formiga & a minha woz $e$ bem fraquinha \\
\hline 17 & buzina soando & minha voz é alta e irritante como uma buzina \\
\hline 18 & & $\begin{array}{l}\text { voz não é muito fina e também não muito } \\
\text { grossa }\end{array}$ \\
\hline 19 & montanha, árvore, pessoss e pássaros & acho minha voz muito falha \\
\hline 20 & rosto e riscos ou linhas saindo da boca & ela $\&$ muito aguda $\theta$ alta \\
\hline 21 & gramado, árvores e péssaros voando & minha voz é como de pássaro: suave e doce \\
\hline 23 & notas musicals & $\begin{array}{l}\text { quando canto ao elevar a voz para o agudo } \\
\text { irrita a pregas vocals e começo a tossir }\end{array}$ \\
\hline 26 & esplga de milho & $\begin{array}{l}\text { palha de milho ressecada (...) sinto que estou } \\
\text { com minhas cordas vocais projudicadas }\end{array}$ \\
\hline 27 & sol, nuvem e mar & $\begin{array}{c}\text { acho que o scm \& lindo, assim como \& indo o } \\
\text { ouvir a som do mar }\end{array}$ \\
\hline 30 & $\begin{array}{l}\text { sol, passaros, árvore com maçâs, menina, } \\
\text { notas musicais, carro. }\end{array}$ & $\begin{array}{l}\text { Carro que desenhei significa que muitas } \\
\text { vezes, cantando, minha voz falha }\end{array}$ \\
\hline 33 & mata e rio & $\begin{array}{l}\text { percebo minha woz como um rio (...) às vezes } \\
\text { flui de modo transparente e limpida e outras } \\
\text { vezes e turva e apresenta nidos indesejàveis }\end{array}$ \\
\hline 34 & sol pássaro girafa & minha voz é alta como da girafa \\
\hline 37 & $\begin{array}{l}\text { bala ardida, corda enrolada, cadeado } \\
\text { fechado e trem rápido apitando }\end{array}$ & $\begin{array}{l}\text { usei a bala ardida porque as vezes arde } \\
\text { minha garganta, geralmente quando } \\
\text { canto, chego até a afogar. }\end{array}$ \\
\hline 38 & árvore colorida, escada e figuras humanas & $\begin{array}{c}\text { minha woz e fina, grossa e alta (...) e mais } \\
\text { para homem. }\end{array}$ \\
\hline 40 & traçados coloridos de eletrocardiograma & $\begin{array}{l}\text { ela tem oscilaçōes como num } \\
\text { eletrocardiograma, ela varia com a } \\
\text { temperatura do nosso corpo; ela e forte e } \\
\text { fraca, como a nossa força cu disposição; } \\
\text { como no desenho, ela tem as suas variaçoes }\end{array}$ \\
\hline 46 & casa, árvore, galinha e uma familia & minha voz $e$ clara \\
\hline 47 & ganso & $\begin{array}{c}\text { Identifico minha woz com o scm de ganso, um } \\
\text { pouco de descontrole no timbre da voz }\end{array}$ \\
\hline 50 & lâpis & $\begin{array}{c}\text { desenhei o lapis, pois se caracteriza com a } \\
\text { minha fala, comeca baixinho e fina de } \\
\text { repente aumenta e quebra. }\end{array}$ \\
\hline $\begin{array}{l}n=28 \\
52,8 \%\end{array}$ & $\begin{array}{c}25 \\
47 \%\end{array}$ & $\begin{array}{c}26 \\
49 \%\end{array}$ \\
\hline
\end{tabular}

\section{Figura 2 - Distribuição dos resultados de desenhos e depoimentos sobre a voz conforme o atributo auditivo-proprioceptivo}




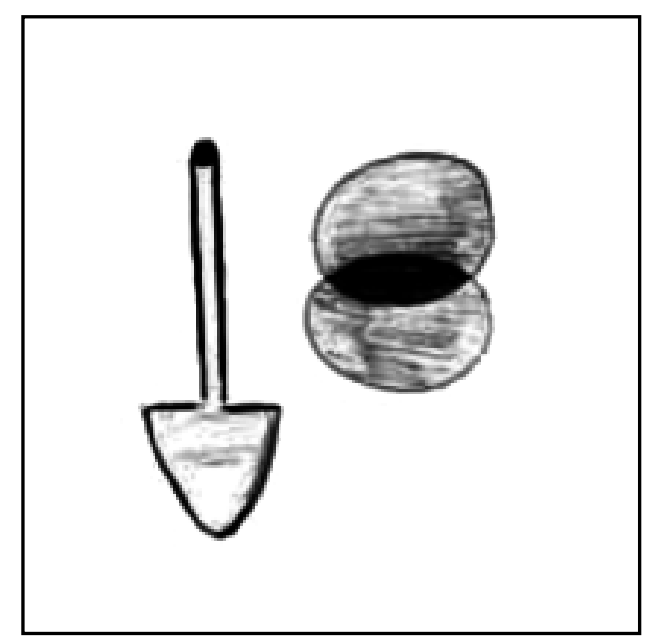

Figura 3 - Desenhos do sujeito 9: atributos sócio-cultural e profissional

\begin{tabular}{|c|c|c|}
\hline \multicolumn{3}{|c|}{ ATRIBUTO SÓCIO-CULTURAL } \\
\hline Suj. & Desenho & Depoimento \\
\hline 3 & aves, flores e colorido & $\begin{array}{l}\text { o canto é uma arte que precisa de vida para emocionar } \\
\text { alguém }\end{array}$ \\
\hline 5 & - & as pessoas não me entendem \\
\hline 9 & circulos unidos coloridos & $\begin{array}{l}\text { os circulos unidos representam o convivio social, onde } \\
\text { minha voz é um vínculo de ligaçăo }\end{array}$ \\
\hline 7 & pipa, céu & $\begin{array}{l}\text { quando canto (...) as pessoas conseguem ficar em } \\
\text { contemplaçăo }\end{array}$ \\
\hline 23 & Nuvem, chuva, raios & eu falo muito rápido tenho dificuldade em comunicar \\
\hline 34 & $\begin{array}{l}\text { bala ardida, corda enrolada, } \\
\text { cadeado fechado e trem rápido } \\
\text { apitando }\end{array}$ & $\begin{array}{c}\text { usei o trem porque, às vezes, falo rápido e as pessoas } \\
\text { nāo me entendem (...) e eu preciso da minha voz } \\
\text { perfeita para agradar anda mais ao meu Deus e näo } \\
\text { deixar ninguém surdo }\end{array}$ \\
\hline 41 & sol, barco e mar & $\begin{array}{c}\text { se participo de uma reuniāo com várias pessoas, sinto } \\
\text { dificuldade de expressar }\end{array}$ \\
\hline 43 & sol & $\begin{array}{c}\text { através da voz levar mensagem positiva, como é } \\
\text { positivo o sol, sua luz sua claridade }\end{array}$ \\
\hline 45 & $\begin{array}{l}\text { sol, duas pessoas unidas por } \\
\text { uma corrente, olho } \\
\text { lacrimejando, faca, flor e boca } \\
\text { sorrindo }\end{array}$ & $\begin{array}{c}\text { considero a voz um elo de ligação entre as pessoas. } \\
\text { Pode ser bela como uma flor, machucar como uma } \\
\text { faca, provocar risos e lágrimas }\end{array}$ \\
\hline $\begin{array}{c}n=9 \\
16,9 \%\end{array}$ & $\begin{array}{c}8 \\
15 \%\end{array}$ & $\begin{array}{c}9 \\
17 \%\end{array}$ \\
\hline
\end{tabular}

Figura 4 - Distribuição dos resultados de desenhos e depoimentos escritos sobre a voz conforme o atributo sócio-cultural 


\section{ATRIBUTO PROFISSIONAL}

\begin{tabular}{|c|c|c|}
\hline Suj. & Desenho & Depoimento \\
\hline 2 & homem cantando e notas musicais & gostaria de melhorá-la tornando um ótimo tenor \\
\hline 9 & pá e círculos coloridos & minha voz é como instrumento de trabalho \\
\hline 43 & sol & ela é importante ferramenta de trabalho \\
\hline $\mathrm{n}=3$ & 3 & 3 \\
$5,6 \%$ & $5,6 \%$ & $5,6 \%$ \\
\hline
\end{tabular}

Figura 5 - Distribuição dos resultados de desenhos e depoimentos escritos sobre a voz conforme o atributo profissional

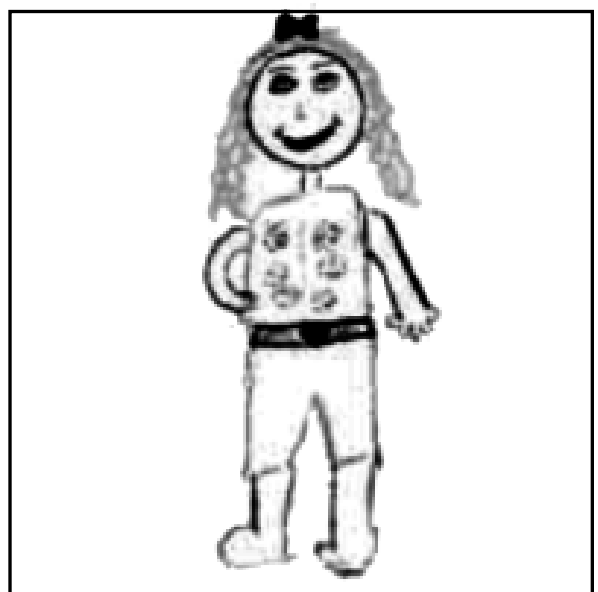

Figura 6 - Desenho do sujeito 4: Atributo psico-emocional

\begin{tabular}{|c|c|c|}
\hline \multicolumn{3}{|r|}{ ATRIBUTO PSICO-EMOCIONAL } \\
\hline Suj. & Desenho & Depoimento \\
\hline 3 & aves, flores e colorido & $\begin{array}{l}\text { o canto é uma arte que precisa de vida para emocionar } \\
\text { alguém }\end{array}$ \\
\hline 4 & $\begin{array}{l}\text { menina com roupa florida e laço } \\
\text { na cabeça }\end{array}$ & eu acho minha voz de criança \\
\hline 24 & vulcāo & é como uma relação sem controle \\
\hline 30 & $\begin{array}{l}\text { Sol, passaros, arvore com } \\
\text { maças, menina, notas musicais } \\
\text { e carro. }\end{array}$ & sinto grande prazer em louvar \\
\hline 37 & Arvore, escada e crianças & minha voz é mais para homem \\
\hline 46 & - & o nervosismo ajuda o descontrole da voz \\
\hline 43 & sol & expressar sentimentos \\
\hline 44 & $\begin{array}{l}\text { sol, nuvem, arvore com frutas e } \\
\text { duas pessoas }\end{array}$ & identifica com voz de criança \\
\hline $\begin{array}{c}n=8 \\
15,0 \%\end{array}$ & $\begin{array}{c}7 \\
13 \% \\
\end{array}$ & $\begin{array}{c}8 \\
15 \% \\
\end{array}$ \\
\hline
\end{tabular}

Figura 7 - Distribuição dos resultados de desenhos e depoimentos escritos sobre a voz conforme o atributo psico-emocional 


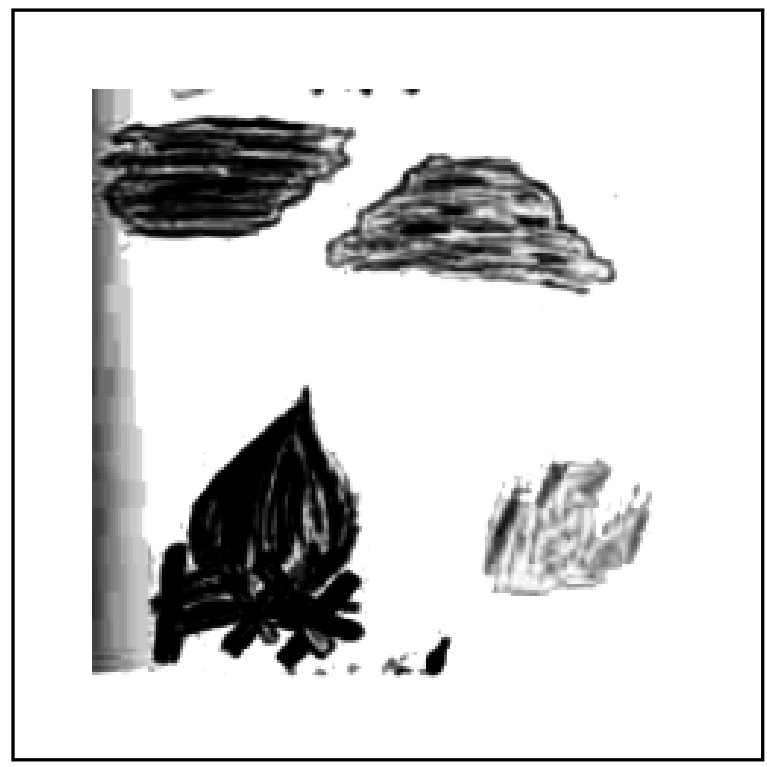

Figura 8 - Desenho do sujeito 8: parâmetro qualidade vocal

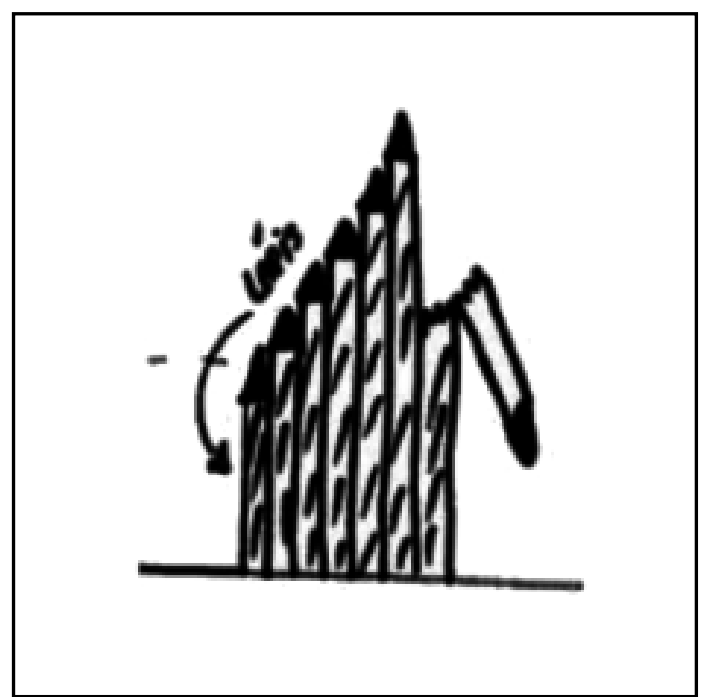

Figura 9 - Desenho do sujeito 47 - parâmetros: loudness, pitch, qualidade vocal e respiração/coordenação pneumofônica 


\begin{tabular}{|c|c|c|c|c|}
\hline \multirow{2}{*}{ Suj. } & \multicolumn{2}{|c|}{ ARTICULAÇĀO } & \multicolumn{2}{|c|}{ LOUDNESS } \\
\hline & DESENHO & DEPOIMENTO & DESENHO & DEPOIMENTO \\
\hline 1 & $\begin{array}{l}\text { pato, árvore, } \\
\text { nuvem e sol }\end{array}$ & $\begin{array}{l}\text { percebi que falava sem } \\
\text { gesticular a boca. }\end{array}$ & - & - \\
\hline 5 & $\begin{array}{l}\text { traçados retos } \\
\text { e espiralados }\end{array}$ & $\begin{array}{l}\text { pela falta de respirar e } \\
\text { falar para dentro as } \\
\text { pessoas não entendem }\end{array}$ & $\cdot$ & - \\
\hline 11 & - & - & $\begin{array}{c}\text { homem soltando a voz } \\
\text { em um poco }\end{array}$ & $\begin{array}{c}\text { minha voz parece que vai } \\
\text { para o fundo do poco }\end{array}$ \\
\hline 12 & $\begin{array}{l}\text { boca aberta } \\
\text { sendo tapada }\end{array}$ & $\begin{array}{c}\text { é como se algo me } \\
\text { impedisse de soltar a voz } \\
\text { para fora e ela entrasse } \\
\text { ao invés de sair }\end{array}$ & (2) & 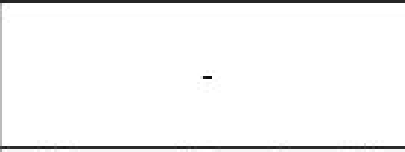 \\
\hline 16 & $=$ & - & árvore e uma formiga & minha voz é bem fraquinha \\
\hline 17 & - & - & buzina soando & $\begin{array}{l}\text { minha voz é alta e irritante } \\
\text { como uma buzina }\end{array}$ \\
\hline 20 & - & - & Rosto, boca e riscos & minha voz é aguda e alta \\
\hline 21 & - & - & pássaro, arvores e rio & $\begin{array}{l}\text { minha voz é como de } \\
\text { pássaro: suave e doce }\end{array}$ \\
\hline 25 & nuvens, troväo & $\begin{array}{c}\text { tenho dificuldade em } \\
\text { comunicar }\end{array}$ & - & 然 \\
\hline 31 & - & (2) & mata e rio & $\begin{array}{l}\text { minha voz é como um rio } \\
\text { (...) hora rasa hora profunda }\end{array}$ \\
\hline 34 & $\begin{array}{c}\text { bala ardida, } \\
\text { corda enrolada, } \\
\text { cadeado } \\
\text { fechado e trem } \\
\text { rápido apitando } \\
\end{array}$ & $\begin{array}{l}\text { usei a corda porque, às } \\
\text { vezes, eu me enrolo no } \\
\text { falar (...) o cadeado } \\
\text { porque, às vezes, prendo } \\
\text { a bochecha para falar }\end{array}$ & $\begin{array}{c}\text { bala ardida, } \\
\text { corda enrolada, } \\
\text { cadeado fechado e } \\
\text { trem rápido apitando }\end{array}$ & $\begin{array}{l}\text { Usei o trem por que (...) às } \\
\text { vezes eu grito sem } \\
\text { perceber. Eu preciso da } \\
\text { minha voz perfeita para não } \\
\text { deixar ninguém surdo }\end{array}$ \\
\hline 36 & coelho & minha pronúncia é rápida & - & - \\
\hline 37 & - & - & arvore, escada, & minha voz é alta \\
\hline 38 & - & - & $\begin{array}{c}\text { traçados de } \\
\text { eletrocardiograma }\end{array}$ & $\begin{array}{l}\text { ela tem oscilaçöes como no } \\
\text { eletrocardiograma (...) é } \\
\text { forte ou fraca como a nossa } \\
\text { força e tem suas variaçōes }\end{array}$ \\
\hline 33 & $=$ & - & sol pássaro, girafa & a minha voz e alta \\
\hline 35 & $\begin{array}{l}\text { ondas, cadeado } \\
\text { fechado } e \\
\text { cadeado aberto }\end{array}$ & $\begin{array}{c}\text { altero demais a } \\
\text { movimentação da língua } \\
\text { (...) a pronuncia também } \\
\text { precisa ser melhorada }\end{array}$ & 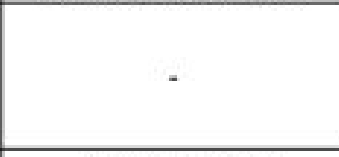 & (2) \\
\hline 41 & sol, barco e mar & Preciso repetir as frases & sol,barco mar & minha voz näo tem volume \\
\hline 42 & - & - & nuvem e trovăo & é como um trovăo \\
\hline 44 & - & - & $\begin{array}{c}\text { sol, nuvem, arvore e } \\
\text { pessoas }\end{array}$ & $\begin{array}{l}\text { eu acho minha voz muito } \\
\text { fina }\end{array}$ \\
\hline 47 & - & $\cdot$ & lápis & $\begin{array}{c}\text { minha voz começa baixinha } \\
\text { e fina; de repente aumenta } \\
\text { e se quebra com falta de } \\
\text { fôlego }\end{array}$ \\
\hline 48 & nuvem coraçäo & minha voz e dificil de sair & nuvem, coração & minha voz é bem baixa \\
\hline 49 & 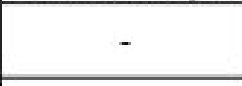 & (2) & arvore & $\begin{array}{c}\text { minha voz é alta como uma } \\
\text { arvore }\end{array}$ \\
\hline 50 & - & - & $\begin{array}{c}\text { riscos ondulados e } \\
\text { estrelas }\end{array}$ & minha voz é baixa \\
\hline 53 & $\begin{array}{l}\text { boca, circulo e } \\
\text { risco }\end{array}$ & $\begin{array}{c}\text { precisa ser trabalhada a } \\
\text { articulaçāo }\end{array}$ & 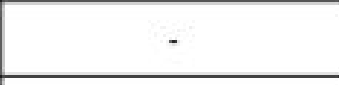 & - \\
\hline $\mathrm{n}=$ & (10) $18,8 \%$ & (10) $18,8 \%$ & (17) $32,06 \%$ & (18) $33,3 \%$ \\
\hline
\end{tabular}

Figura 10 - Distribuição dos resultados da análise de desenhos e depoimentos segundo os parâmetros vocais de articulação e loudness 


\begin{tabular}{|c|c|c|c|c|}
\hline \multirow{2}{*}{ Suj. } & \multicolumn{2}{|c|}{ QUALIDADE VOCAL } & \multicolumn{2}{|c|}{ PITCH } \\
\hline & DESENHO & DEPOIMENTO & DESENHO & DEPOIMENTO \\
\hline 2 & notas musicais & eu considero minha voz estável & - & - \\
\hline 3 & - & 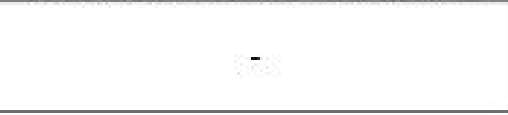 & $\begin{array}{c}\text { menina, roupa } \\
\text { florida e laço na } \\
\text { cabeça }\end{array}$ & acho minha voz de criança \\
\hline 6 & $\begin{array}{l}\text { boca, notas } \\
\text { musicais, } \\
\text { mulher } \\
\text { cantando }\end{array}$ & minha voz é bonita & $\begin{array}{l}\text { boca, notas } \\
\text { musicais, mulher } \\
\text { cantando }\end{array}$ & $\begin{array}{c}\text { mas é muito dificil de alcançar } \\
\text { a altura }\end{array}$ \\
\hline 8 & $\begin{array}{l}\text { fogueira, lenha } \\
\text { e nuvens }\end{array}$ & $\begin{array}{l}\text { A minha voz é como o fogo: apaga } \\
\text { e acende; precisa de lenha para se } \\
\text { manter, só que a minha fogueira } \\
\text { nunca se mantém no mesmo nivel. } \\
\text { Quando necessito que a chama se } \\
\text { mantenha ela me deixa na mão. }\end{array}$ & - & - \\
\hline 10 & $\begin{array}{l}\text { quarto, cama, } \\
\text { pés }\end{array}$ & $\begin{array}{l}\text { minha voz parece com grenilhos } \\
\text { de um quarto de motel }\end{array}$ & - & - \\
\hline 11 & buzina soando & $\begin{array}{c}\text { minha voz } e \text { alta e irritante como } \\
\text { uma buzina }\end{array}$ & - & - \\
\hline 13 & $\begin{array}{l}\text { montanha, } \\
\text { árvore, } \\
\text { pessoas, sol e } \\
\text { pássaros }\end{array}$ & $\begin{array}{l}\text { minha voz precisa de muitos } \\
\text { ajustes pois tenho algumas falas e } \\
\text { preciso consertar, como ficar rouco } \\
\text { e ter dificuldade para subir de tons }\end{array}$ & $\begin{array}{l}\text { montanha, } \\
\text { árvore, pessoas, } \\
\text { sol e pássaros }\end{array}$ & $\begin{array}{l}\text { ter dificuldade para subir de } \\
\text { tons }\end{array}$ \\
\hline 18 & - & - & - & $\begin{array}{l}\text { minha voz não é muito fina nem } \\
\text { muito grossa }\end{array}$ \\
\hline 19 & $\begin{array}{l}\text { aviäo caindo } \\
\text { fumaça }\end{array}$ & acho minha voz muito falha & - & 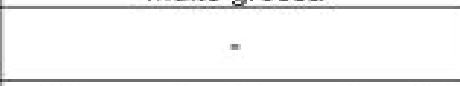 \\
\hline 20 & $\cdot$ & - & $\begin{array}{l}\text { rosto e riscos } \\
\text { saindo da boca }\end{array}$ & minha voz é muito aguda e alta \\
\hline 22 & $\begin{array}{l}\text { carro, chuva e } \\
\text { raios. Notas } \\
\text { musicais } \\
\text { saindo do } \\
\text { escapamento }\end{array}$ & $\begin{array}{c}\text { a chuva toda quebradinha é } \\
\text { porque sinto minha voz assim } \\
\text { no fim do dia: falhal }\end{array}$ & $\begin{array}{l}\text { carro, chuva e } \\
\text { raios. Notas } \\
\text { musicais saindo } \\
\text { do escapamento }\end{array}$ & $\begin{array}{c}\text { O carro e os raios porque } \\
\text { também a acho meio grave e } \\
\text { descompassada }\end{array}$ \\
\hline 23 & - & - & escala musical & $\begin{array}{l}\text { sinto dificuldade em elevar a } \\
\text { voz para o agudo }\end{array}$ \\
\hline 37 & - & - & $\begin{array}{l}\text { árvore, escada e } \\
\text { crianças }\end{array}$ & minha voz é fina e grossa \\
\hline 29 & - & - & $\begin{array}{l}\text { sol, metade de } \\
\text { um corpo }\end{array}$ & quando falo ela é grave \\
\hline 31 & mata e rio & $\begin{array}{l}\text { percebo minha voz como um rio } \\
\text { (...) hora flui de modo transparente } \\
\text { e limpida, outras vezes é turva e } \\
\text { apresenta ruidos indesejáveis }\end{array}$ & mata e rio & $\begin{array}{l}\text { percebo minha voz como um } \\
\text { rio (...) hora é mais grossa, } \\
\text { hora è mais fina }\end{array}$ \\
\hline 32 & $\begin{array}{l}\text { Nota de } \\
\text { R } \$ 100,00\end{array}$ & $\begin{array}{l}\text { assim como o dinheiro a minha } \\
\text { voz acaba rápido }\end{array}$ & - & $\cdot$ \\
\hline 44 & - & $\cdot$ & $\begin{array}{l}\text { sol, nuvem, } \\
\text { arvore e pessoas }\end{array}$ & eu acho minha voz muito fina \\
\hline 47 & lápis & $\begin{array}{l}\text { minha voz começa baixinha e fina; } \\
\text { de repente aumenta e se quebra } \\
\text { com falta de fỏlego. }\end{array}$ & lápis & $\begin{array}{c}\text { minha voz começa baixinha e } \\
\text { fina; de repente aumenta e se } \\
\text { quebra com falta de fölego. }\end{array}$ \\
\hline 51 & $\cdot$ & - & raios, nuvens & minha voz transmite som grave \\
\hline 52 & - & - & notas musicais & minha voz e muito fina \\
\hline
\end{tabular}

Figura 11 - Distribuição dos resultados da análise de desenhos e depoimentos segundo os parâmetros vocais: qualidade vocal e pitch 


\begin{tabular}{|c|c|c|c|c|c|c|}
\hline \multirow[t]{2}{*}{ Suj } & \multicolumn{2}{|c|}{$\begin{array}{l}\text { RESPIRAÇÃO E } \\
\text { COORDENAÇÃO } \\
\text { PNEUMOFÔNICA }\end{array}$} & \multicolumn{2}{|c|}{ VELOCIDADE DE FALA } & \multicolumn{2}{|c|}{ RESSONÂNCIA } \\
\hline & DESENHO & DEPOIMENTO & DESENHO & DEPOIMENTO & DESENHO & DEPOIMENTO \\
\hline 1 & - & - & - & - & pato & $\begin{array}{c}\text { minha voz } \\
\text { parece de pato }\end{array}$ \\
\hline 5 & $\begin{array}{l}\text { traçado } \\
\text { reto e } \\
\text { espiralado }\end{array}$ & $\begin{array}{c}\text { pela falta de } \\
\text { respirar (...) } \\
\text { cantando consigo } \\
\text { pouco usar o } \\
\text { diafragma de forma } \\
\text { correta }\end{array}$ & - & - & $\begin{array}{l}\text { traçado } \\
\text { reto e } \\
\text { espiralado }\end{array}$ & $\begin{array}{c}\text { pela falta de } \\
\text { respirar e falar } \\
\text { para dentro e } \\
\text { năo para fora } \\
\text { as pessoas nāo } \\
\text { me entendem }\end{array}$ \\
\hline 25 & - & - & $\begin{array}{c}\text { nuvens raios } \\
\text { e chuva }\end{array}$ & falo muito rápido & - & 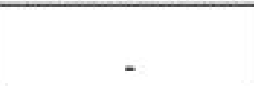 \\
\hline 32 & $\begin{array}{c}\text { Nota de } \\
\text { R\$ } 100,00\end{array}$ & $\begin{array}{c}\text { assim como o } \\
\text { dinheiro a minha } \\
\text { voz acaba rápido } \\
\text { (...) é que eu näo } \\
\text { respirava quando } \\
\text { estava em } \\
\text { alguma conversa } \\
\text { empolgada }\end{array}$ & - & - & - & - \\
\hline 36 & - & - & coelho & $\begin{array}{l}\text { minha voz é } \\
\text { rapida }\end{array}$ & - & - \\
\hline 34 & - & - & $\begin{array}{l}\text { bala ardida, } \\
\text { corda } \\
\text { enrolada, } \\
\text { cadeado } \\
\text { fechado e } \\
\text { trem rápido } \\
\text { apitando }\end{array}$ & $\begin{array}{l}\text { usei o trem } \\
\text { porque, às } \\
\text { vezes, falo } \\
\text { rápido e as } \\
\text { pessoas nāo me } \\
\text { entendem }\end{array}$ & - & - \\
\hline 35 & $\begin{array}{c}\text { ondas, } \\
\text { cadeado } \\
\text { fechado e } \\
\text { cadeado } \\
\text { aberto } \\
\end{array}$ & $\begin{array}{l}\text { não estou dando } \\
\text { suporte } \\
\text { diafragmático }\end{array}$ & - & - & - & - \\
\hline 46 & - & - & - & - & ganso & $\begin{array}{c}\text { descontrole no } \\
\text { timbre da voz e } \\
\text { também um } \\
\text { tanto fanhosa }\end{array}$ \\
\hline 47 & lápis & $\begin{array}{l}\text { minha voz começa } \\
\text { baixinha e fina; de } \\
\text { repente aumenta e } \\
\text { se quebra com } \\
\text { falta de follego }\end{array}$ & - & - & - & - \\
\hline 53 & $\begin{array}{l}\text { boca, } \\
\text { circulo e } \\
\text { um risco }\end{array}$ & $\begin{array}{c}\text { representa minha } \\
\text { fala no cotidiano } \\
\text { fazendo pausa } \\
\text { para respirar }\end{array}$ & & & & \\
\hline \multirow[t]{2}{*}{$\begin{array}{l}n=9 \\
17 \%\end{array}$} & $\begin{array}{c}4 \\
7,48 \% \\
\end{array}$ & $\begin{array}{c}5 \\
9,43 \% \\
\end{array}$ & $\begin{array}{c}3 \\
5,6 \%\end{array}$ & $\begin{array}{c}3 \\
5,6 \%\end{array}$ & $\begin{array}{c}3 \\
5,6 \% \\
\end{array}$ & $\begin{array}{c}3 \\
5,6 \% \\
\end{array}$ \\
\hline & \multicolumn{2}{|c|}{$16,9 \%$} & \multicolumn{2}{|r|}{$11,2 \%$} & \multicolumn{2}{|c|}{$11,2 \%$} \\
\hline
\end{tabular}

Figura 12 - Distribuição dos resultados da análise de desenhos e depoimentos segundo os parâmetros vocais: respiração/ coordenação pneumofônica, velocidade de fala e ressonância 


\section{DISCUSSÃO}

Os resultados demonstraram que a maioria dos sujeitos foi capaz de expressar suas percepções a respeito da imagem e valoração da voz por meio do desenho e dos depoimentos, e a maior ocorrência de depoimentos sugere que a linguagem escrita parece oferecer maiores possibilidades para se expressar percepções e impressões sobre a imagem/valoração voz. Desta maneira, desenhos e depoimentos escritos podem se configurar como recursos de linguagem e possibilidades simbólicas para a expressão das percepções subjetivas e a análise e avaliação da imagem vocal e da valoração da voz.

Os achados encontram-se em conformidade com estudos com professores ${ }^{25-28}$ e com estudantes de Jornalismo ${ }^{18}$ que se valeram de depoimentos para a identificação da imagem vocal. A imagem vocal e a valoração da voz são aspectos relevantes na análise e avaliação de profissionais da voz, os quais podem atribuir valorações e importâncias distintas à voz, em conformidade com as variações perceptivas individuais e as características, demandas e necessidades de uso da voz em cada categoria ${ }^{2,29}$.

No contexto das ações educativas em saúde vocal, o fonoaudiólogo deve buscar conhecer a imagem e a valoração que os sujeitos têm a respeito da própria voz, a fim de conhecer e melhor adequar tais ações às percepções, expectativas, saberes, conhecimentos, necessidades e realidades daqueles aos quais elas se dirigem. Isso deve ser feito levando-se em conta que as maneiras pelas quais os sujeitos percebem, representam e lidam com o seu processo saúdedoença-cuidado são determinadas por seus conhecimentos, experiências, cultura e historicidade e que as educativas em saúde devem favorecer a expressão desses aspectos num processo de trocas entre os envolvidos ${ }^{3}$.

Na Figura 1 se visualiza a grande ocorrência de atributos auditivo-proprioceptivos, tanto no desenho como no depoimento, ainda que predominante neste último. Ou seja: este é o atributo mais percebido e referido pelas duas modalidades gráficas. A ocorrência deste atributo afirma os achados de estudos anteriores ${ }^{18,19}$ e confirma a importância da sua percepção nas ações fonoaudiológicas, pois as capacidades de ouvir e de discriminar a própria voz são muito valorizadas quando se trata de promover mudanças da qualidade vocal.

A correspondência entre os sentidos das representações gráficas dos desenhos (figuras, formas e cores) e dos depoimentos escritos (texto, frases e palavras) é evidente nas Figuras 4, 5 e 7, indicando a complementaridade entre linguagens - desenho, fala e escrita ${ }^{22} \mathrm{e}$ confirmando a importância do desenho e depoimento como formas de expressão da subjetividade, da percepção e dos conhecimentos dos sujeitos sobre a voz. Os atos de desenhar e de escrever sobre a própria voz são oportunidades para os sujeitos pensarem sobre a voz, as maneiras pelas quais a percebem, os usos que fazem dela, as suas características e os aspectos intervenientes na saúde e qualidade vocal.

Os círculos da Figura 3 e os resultados da Figura 4 afirmam o foco nos aspectos relacionais, comunicação e nos impactos da voz sobre o outro, confirmando a importância da voz como componente relevante para a comunicação interpessoal e responsável pelo sucesso das interações humanas ${ }^{2,3,15,26}$.

A análise das Figuras 4 e 7 articulam-se no que diz respeito às produções do sujeito 3 , ou seja, as aves cantam e representam o cantor; as flores e o colorido representam a vida, a sensibilidade e as emoções; o canto, enquanto forma de manifestação artística, exprime características da sociedade e da cultura em que se insere e, ao dirigir-se para alguém, uma platéia ou público específico, provoca uma relação entre o cantor e seu ouvinte provocando reações e emoções. Assim, desenho e depoimento do sujeito 3 exprimem a junção dos atributos: sócio-cultural e psico-emocional - este último representando a importância da relação entre a qualidade vocal e os aspectos subjetivos, de ordem psicológica, afetiva e emocional do falante ${ }^{15,26}$ (Figuras 6 e 7).

Desenhos e depoimentos dos sujeitos 2 e 9 (Figuras 3 e 5) se complementam na representatividade da voz como ferramenta/instrumento de trabalho e de qualificação profissional, confirmando que estes podem revelar aspectos do uso profissional da voz dos sujeitos e auxiliar o fonoaudiólogo no direcionamento das ações de promoção da saúde vocal, já que a voz merece atenção específica em função das necessidades, particularidades e singularidades de cada categoria profissional ${ }^{2,15,26,29}$.

As Figuras 10, 11 e 12 demonstraram que os parâmetros vocais que ocorreram com maior freqüência foram os de loudness, pitch, articulação e qualidade vocal, o que sugere ser aqueles os parâmetros sobre os quais recaem, mais facilmente, a atenção, a crítica e as queixas dos sujeitos.

Estudos ${ }^{26}$ que abordam a psicodinâmica vocal ajudam a compreender a importância da avaliação destes parâmetros e de como o sujeito percebe os impactos deles na sua comunicação.

Neste sentido, a loudness possui relação com a manifestação da personalidade e temperamento da pessoa, bem como com as maneiras como ela lida com a noção de limite próprio e do outro ${ }^{26}$.

Já o pitch diz respeito à altura de um som e tem ligação direta com a personalidade do falante (vozes graves se relacionam a indivíduos autoritários e energéticos e vozes agudas a pessoas dependentes, infantis e frágeis) e com a intenção do discurso 
(alegria pode ser expressa por meio de tons mais agudos e a tristeza por tons mais graves) ${ }^{26}$.

Uma articulação ampla, clara e bem definida confere credibilidade, favorece a projeção vocal, evita o esforço à fonação e permite ao falante transmitir uma sensação de franqueza, desejo de ser compreendido e clareza de idéias ${ }^{26}$.

Por fim, a qualidade vocal é o conjunto de características que identificam a voz humana e fornece impressões e informações sobre o falante, nas dimensões biológica, psicológica, sócioeducacional, profissional, bem como a presença ou não de uma disfonia ${ }^{26}$.

Nota-se que alguns sujeitos $(1,4,6,11$ e 13) referem dois ou mais parâmetros vocais e que não houve desenhos ou depoimentos que pudessem ser relacionados aos parâmetros de modulação e ataque vocal, o que sugere que estes últimos parâmetros não são facilmente percebidos pelos sujeitos.

$O$ fato de a qualidade vocal ser expressa tanto pelo desenho como pela escrita demonstra as capacidades dos sujeitos em refletir sobre a própria voz e manifestar as impressões e percepções a ela relacionadas. Isso mostra que o saber popular abarca conteúdos, informações e percepções importantes de serem conhecidas e levadas em conta nas ações em saúde vocal e que a oportunidade de desenhar e escrever sobre a voz se apresenta como possibilidade de expressar esses aspectos na perspectiva de se estabelecer canais para o diálogo entre a percepção do fonoaudiólogo e a dos sujeitos, ou seja, entre os saberes acadêmico/científico e comunitário/popular, em conformidade com estudos anteriores ${ }^{3}$. Sugere-se a realização de pesquisas futuras focadas nesta temática.

\section{CONCLUSÃO}

Em geral houve correspondência entre os sentidos das representações gráficas dos desenhos e dos depoimentos sobre a voz, confirmando a interação entre essas duas formas de linguagem nas possibilidades de expressão das percepções, pensamentos, conhecimentos, emoções e experiências relacionadas com a voz/saúde vocal.

Desenhos e depoimentos sobre a voz se mostram como recursos que podem possibilitar a expressão e o conhecimento vocal dos sujeitos e precisam ser melhores explorados nas ações educativas, terapêuticas e assessorias fonoaudiológicas que prezam pela valorização e troca de saberes, pelo diálogo e pela participação ativa dos sujeitos.

O estudo aponta um caminho no sentido de se construir canais de expressão e relações dialógicas nas ações Fonoaudiológicas de maneira a se considerar as percepções e os saberes dos sujeitos envolvidos nas ações.

\section{ABSTRACT}

Purpose: to characterize the aspects of perception and vocal recognition in voice training groups through the participants' drawings and statements about voice. Methods: documental analysis of final reports from four Voice Training groups which took place in the probationary period in Community Speech-Language-Pathology I and II of one Speech-Language-Pathology course for the analysis of content of the drawings and statements written by 53 subjects. Results: the categories identified by the analysis of drawings and statements were: vocal image or value attributed to voice - with a positive image/value prevailing in the drawings and negative one in the statements. As for vocal attributes, the auditive-proprioceptive attribute prevailed, whereas there was less stress on sociocultural, psycho-emotional and professional attributes. Vocal parameters with higher occurrence were loudness, pitch, articulation and vocal quality. Conclusion: drawings and statements written about voice are showed as resources which can enable the expression of perception and knowledge of the subjects about their voice and need to be better explored in educational and speech and language training areas which have the exchange of knowledge, dialogs and active participation of subjects in high regard and are coherent with the health-promoting perspective.

KEYWORDS: Voice; Health Promotion; Health Education

\section{REFERÊNCIAS}

1.Souza TMT, Ferreira LP. Um século de cuidados com a voz profissional falada: a contribuição da fonoaudiologia. Rev Soc Bras Fonoaudiol. 1998; 2(1):26-35.
2. Ferreira LP. Assessoria fonoaudiológica aos profissionais da voz. fonoaudiológica. In: Ferreira LP, BefiLopes D, Limongi SCO, organizadores. Tratado de fonoaudiologia. São Paulo: Roca; 2004. p. 138-47. 3.Penteado RZ, Maróstica AF, Oliveira NBF, Teixeira 
VK, Tonon VA, Soares MA, Dias JC. Saúde vocal: pensando ação educativa nos grupos de vivência de voz. Saúde Rev. 2005; 7(16):55-6.

4.Penteado RZ, Servilha EAM. Fonoaudiológia em saúde pública/coletiva: compreendendo prevenção e o paradigma da promoção da saúde. Disturb Comun. 2004; 16(1):107-16.

5.Penteado RZ, Chun RYS, Silva RC. Do higienismo às ações promotoras de saúde: a trajetória em saúde vocal. Disturb Comun. 2005; 17(1):9-17.

6.Buss PM. Promoção da saúde e qualidade de vida. Ciência Saúde Coletiva. 2000; 5:163-78.

7.Marin CR, Chun RYS, Silva RC, Fedosse E, Leonelli BS. Promoção da saúde em fonoauduiologia: ações coletivas em equipamentos de saúde e de educação. Rev Soc Bras Fonoaudiol. 2003; 8(1):35-41.

8.Wallerstein N. Powerlessness, empowerment and health: implications for health promotion programs. Am J Health Promot. 1992; 6(3):197-205.

9. Wallerstein N. Empowerment to reduce health disparities. Scand J Public Health Suppl. 2002; 59:72-7. 10. Wallerstein N, Bernstein E. Introduction to community empowerment, participatory education and health. Health Educ Q. 1994; 21(2):141-8.

11. Pereira IMTB, Penteado RZ, Marcelo VC. Promoção da saúde e educação em saúde: uma parceria saudável. Mundo da Saúde. 2000; 24:39-44.

12. Williams L, Labonte R, O'Brien M. Empowering social action through narratives of identity and culture. Health Promot Int. 2003; 18(1):33-40.

13. Carvalho SR. Os múltiplos sentidos da categoria empowerment no projeto de promoção da saúde. Cad Saúde Pública. 2004; 20(4):1088-95.

14. Freudenberg N. Community capacity for environmental health promotion: determinants and implications for practice. Health Educ Behav. 2004; 31(4):472-90.

15. Rosen DC, Sataloff RT. Perceived voice loss in professional voice users: principles and case studies with guided drawing assingnmentes. In: Rosen DC, Sataloff RT. Psychology of voice disorders. San Diego: Singular Publishing; 1997. p. 185-242.

16. Luchesi K, Reily L. O papel do desenho na clinica fonoaudiológica: profissionais falam sobre a pratica. [CD-ROM] Rev Soc Bras Fonoaudiol.: Suplemento Especial. Santos; 2005.

\section{RECEBIDO EM: 04/05/2007 \\ ACEITO EM: 25/07/2007}

Endereço para correspondência:

Av. 41, 209 ap. 62

Rio Claro - SP

CEP: $13501-190$

Tel: (19) 35346144

E-mail: rzpenteado@unimep.br
17. Costa ACM, Simaika CR, Oliveira IB. Desenhos de crianças disfônicas: análise da compreensão do processo terapêutico fonoaudiológico. [CD-ROM] Rev Soc Bras Fonoaudiol.: Suplemento Especial. Salvador; 2006.

18. Santos LMA, Chun RYS. Promoção da saúde em jornalismo: o conhecimento do aluno de jornalismo sobre sua voz. [CD-ROM] $2^{\mathrm{a}}$ Mostra Acadêmica UNIMEP. Piracicaba; 2004.

19. Santos LMA, Sanches MH, Chun RYS, Servilha EAM. Promoção da saúde em jornalismo: o conhecimento do aluno de jornalismo sobre sua voz. [CD-ROM] Rev Soc Bras Fonoaudiol.: Suplemento Especial. Foz do Iguaçu; 2004.

20. Silva SMC. Social conditions of the constitutions of infantile drawing. Psicol USP. 1998; 9(2):205-20.

21. Sartain SA, Clarke CL, Heyman R. Hearing the voices of children with chronic illness. J Adv Nurs. 2000; 32(4):913-21.

22. Araújo CC, Lacerda C. Linguagem e desenho uma parceria promissora na clínica fonoaudiológica. Temas Desenvolv. 2002; 11(65):10-9.

23. Lauritzen SO. Lay voices on allergic conditions in children: parents' narratives and the negotiation of a diagnosis. Soc Sci Med. 2004; 58(7):1299-308.

24. Driessnack M. Children's drawings as facilitators of communication: a meta-analysis. J Pediatr Nurs. 2005; 20(6):415-23.

25. Penteado RZ, Rossi D. Vivência de voz e percepções de professores sobre saúde vocal e trabalho. Saúde Rev. 2006; 18(8):32-47.

26. Behlau M, Madázio G, Feijó D, Pontes P. Avaliação de voz. In: Behlau M, organizador. Voz: o livro do especialista I. Rio de Janeiro: Revinter; 2001. p. 118- 20.

27. Simões M, Latorre MRDO. Alteração vocal em professores: uma revisão. J Bras Fonoaudiol. 2002; 3(11):127-34.

28. Schwarz K, Cielo CA. A voz e as condições de trabalho de professores de cidades pequenas do Rio Grande do Sul. Rev Soc Bras Fonoaudiol. 2005; 10(2):83-90.

29. Behlau M. Vozes preferidas: considerações sobre as opções vocais nas profissões. Fono Atual. 2001; 4(16):10-4. 